This item was submitted to Loughborough's Research Repository by the author.

Items in Figshare are protected by copyright, with all rights reserved, unless otherwise indicated.

\title{
Putting a price tag on novel autologous cellular therapies
}

\section{PLEASE CITE THE PUBLISHED VERSION}

http://dx.doi.org/10.1016/j.jcyt.2016.05.005

\section{PUBLISHER}

() International Society for Cellular Therapy. Published by Elsevier Inc.

\section{VERSION}

AM (Accepted Manuscript)

\section{PUBLISHER STATEMENT}

This work is made available according to the conditions of the Creative Commons Attribution-NonCommercialNoDerivatives 4.0 International (CC BY-NC-ND 4.0) licence. Full details of this licence are available at: https://creativecommons.org/licenses/by-nc-nd/4.0/

\section{LICENCE}

CC BY-NC-ND 4.0

\section{REPOSITORY RECORD}

Abou-El-Enein, Mohamed, Gerhard Bauer, Nick Medcalf, Hans-Dieter Volk, and Petra Reinke. 2019. "Putting a Price Tag on Novel Autologous Cellular Therapies". figshare. https://hdl.handle.net/2134/21921. 
Title: Putting a price tag on novel autologous cellular therapies

\section{Authors:}

Mohamed Abou-El-Enein ${ }^{1,5}$, Gerhard Bauer ${ }^{2}$, Nicholas Medcalf ${ }^{3}$ Hans-Dieter Volk ${ }^{1}{ }^{4}$, Petra Reinke ${ }^{1,5}$ 1- Berlin-Brandenburg Center for Regenerative Therapies (BCRT), Charité University Medicine, Campus Virchow, Berlin, Germany

2-University of California Davis, Institute for Regenerative Cures (IRC) Sacramento, CA, USA

3-Wolfson School of Mechanical, Electrical and Manufacturing Engineering, Loughborough University, Loughborough, LE11 3TU, UK

4- Institute of Medical Immunology, Charité University Medicine, Campus Virchow, Berlin, Germany.

5- Department of Nephrology and Internal Intensive Care, Charité-University Medicine, Campus Virchow, Berlin, Germany.

Address of corresponding author: Dr. M. Abou-El-Enein, BCRT, Clinical Development Platform, Charité - University Medicine, Campus Virchow, Augustenburger Platz 1, D-13353 Berlin, Germany.

Phone: 0049/030-450-539594

Fax: 0049/030-450-524959

Email: Mohamed.abou-el-enein@charite.de

\section{Abstract}

Cell therapies, especially autologous therapies, pose significant challenges to researchers who wish to move from small, probably academic, methods of manufacture to full commercial scale. There is a dearth of reliable information about the costs of operation, and this makes it difficult to predict with confidence the investment needed to translate the innovations to the clinic, other than as small-scale, clinician-led prescriptions. Here, we provide an example of the results of a cost model that takes into account the fixed and variable costs of manufacture of one such therapy. We also highlight the different factors that influence the product final pricing strategy. Our findings illustrate the need for cooperative and collective action by the research community in pre-competitive research to generate the operational models that are much needed to increase confidence in process development for these advanced products.

\section{Key Words:}

Immunotherapy, Adoptive T Cell Therapy, Reimbursement, Commercialization, Regulation, Market Adoption, Cost of Goods, Good Manufacturing Practice, Scale-Up, Price

Word Count: 2900 
In the past decade, there has been a rapid increase in the development of autologous cell therapies, with several investigational products demonstrating encouraging clinical outcomes, especially in immunotherapies. It has been recognized, for instance, that adoptive transfer of in vitro expanded virus-specific $\mathrm{T}$ cells can prevent and also effectively treat viral infectious complications in immunocompromised patients after solid organs (SOT) or hematopoietic stem-cell transplantation (HSCT) (1-4). Infectious complications that arise due to immunosuppression, that organ recipients need for the lifetime of the transplanted organ to prevent rejection, are mainly caused by the cytomegalovirus (CMV), BK virus, and the Epstein - Barr virus (EBV) (5). Although the adoption of universal antiviral prophylactic strategies has significantly reduced the incidence of CMV infection and disease, the development of drugresistant and late-onset CMV disease after discontinuation of these prophylactic antivirals is prone to high risk of malignancy, graft loss and mortality (6), and associated with a significant rise in treatment costs (7). Additionally, other serious adverse events such as nephrotoxicity and neutropenia can also result from the administration of antiviral agents (8). Thus, adoptive immunotherapies associated with lower toxicities for the prevention and treatment of CMV infection and disease are highly needed and may also produce overall cost savings in posttransplant patient care. Indeed, a recent study has suggested that even if the prevention capabilities of antiviral donor-derived cytotoxic T lymphocytes (CTL) in HSCT, which cost $\$ 10,000$ to manufacture, would only be $50 \%$ effective at avoiding the need for antiviral treatment, it is still considered the less expensive option compared to the cost of antiviral treatment and associated hospital care of more than $\$ 50,000$ per patient (9). Researchers working in this field anticipate that such therapies could replace conventional treatments, possibly allowing this novel therapeutic category to be accepted as standard practice (10). However, if these products are to find their way into routine clinical practice, obvious hurdles associated with their lengthy development timelines, pricing, reimbursement and commercialization need to be addressed and overcome. We sought to identify and describe some of these challenges from the perspective of academic institutions developing these advanced therapies. We are also providing a relevant case study to illustrate a detailed measure of manufacturing costs of a CMV-specific T cell immunotherapy.

\section{Developing a tailored business model for cell therapies}

Autologous cell therapies are patient-specific products that require a considerable degree of flexibility in their manufacturing process, while following the principles of Good Manufacturing Practice (GMP), as mandated by regulations (11) and guidelines (12). Any 
business models developed for the commercialization of autologous therapies therefore differ substantially from those used for small molecule drugs or other biologics. In order to compete with small molecule pharmaceuticals on the market, which are normally cheaper to manufacture, autologous cell therapies need to demonstrate superior safety and at least equivalent, if not better efficacy as compared to the available standard of care, or should be applicable in diseases with no available therapeutic treatments. Interestingly, setting a market price for autologous cellular therapies is very ambitious where complex supply logistics, the need to scale out, rather than scale up, production and the lack of transparency of the production costs, due to the large variety of manufacturing operations, are characteristic of the sector. A significant cost contribution also arises from the fixed manufacturing overhead costs and these can be difficult to quantify without detailed studies. Therefore, new and tailored prospective economic models are required for autologous cell therapy products that focus rather on optimizing the operational efficiency while reducing risks associated with the manufacturing process $(13,14)$. By reducing the manufacturing costs of these products, which are typically driven by sophisticated manufacturing facilities, highly trained labor, expensive materials and high overheads for assurance of quality, the final price tag of autologous cell therapies can reach a more affordable level (15).

Several authors of this paper reported in 2013 a novel cost model (CTAT or Clean Technology Assessment Technique) that integrates manufacturing economics and optimization approaches to accurately assess the optimal cost of producing a clinical grade cell therapy product (13). The possible strength of this proposed model lies in the vigorous approach to splitting the interdependence between costs resulting from operating a GMP facility and those resulting from manufacturing a specific cellular product. Although annual direct and indirect operating costs represented in personnel, utilities, maintenance, quality management system, materials and supplies are already covered by the model, additional costs that can result from expanding the infrastructure and purchasing new equipment to accommodate increased demand for production, need to be included in a sequential application of the model. CTAT is also dependent upon local and regional cost variations for materials and services, limited to the manufacturing costs of the therapy, and does not account for costs of research and development (R\&D). Nevertheless, the model may still help to provide a snapshot of the commercial viability of cell- and gene therapies by accurately estimating the cost of goods (CoG). Without any doubt, if such products are to be introduced into the pharmaceutical market, their price will be severalfold higher than the $\mathrm{CoG}$ in order to cover R\&D costs, expenses incurred in translational research and marketing, plus generating a profit, which is essential for the developer`s survival 
and growth. In order to make the cost assumptions in such a tailored business model robust enough to support ongoing sustainability and to increase the applicability of its results, the key cost drivers in the manufacturing of cell therapy products should be examined and understood.

\section{Identifying the key cost drivers in manufacturing cell therapies}

The relevant manufacturing costs of cellular products can be broken down into direct (variable) and indirect (fixed) costs. Material, personnel costs, and process validation costs are examples of direct costs that have a variable cost share, depending on the manufacturing volume. Preventive maintenance, amortization of facility and equipment capital purchases and environmental monitoring are examples of indirect costs which have a fixed cost share, independent of actual GMP facility utilization times for product manufacturing. For the total variable costs, the cost driver is the number of manufacturing runs carried out in the facility. For the total fixed costs, cost drivers are GMP facility size, personnel wages (including support services such as finance, marketing, maintenance and legal services) and the degree of optimization of the manufacturing process, including the failure and wastage rate of batch production. For most cellular therapies, the major cost driver for the unit fixed cost (the cost of a single therapeutic cellular product), is the duration of the manufacturing process. An increase in product manufacturing time results in a linear increase in fixed costs. For products that need only little manufacturing time, variable costs are the dominant cost share. Nevertheless, other aspects, such as costs for scale-up equipment, dedicated to only some of the manufactured products, can still contribute to a higher percentage of costs than the GMP manufacturing time.

It is apparent that the scale of manufacturing is another important cost driver in the production process of cell therapies (14). Usually, calculating the production capacity of a manufacturing facility should be based on a supply and demand relationship. In most of the cost modeling efforts, capacity constraints are ignored and production costs are assumed to be linear, thereby limiting the degree to which costs are realistic. This is often done since accounting for production scale economy can significantly complicate the pricing process of a product. Such activity does not come easily to those without prior experience of the process in question or without operational management experience. Since increasing production levels reduces the contribution of the fixed costs of operating GMP facilities to the manufacturing cost per unit, developers always aim to improve their scale-up capabilities. For instance, in a phase I or I/II clinical trial investigating an autologous therapeutic cellular product, more than two products could be manufactured per incubator given good physical separation and changeover procedures after product manufacturing cycles. If closed systems are used, such as the Octane 
Cocoon (Octane Biotech Inc.) (16) or the G-Rex M (Wilson Wolf Manufacturing) (17) bioreactor platforms, only spatial limits and points in the process where manual handling imposes a bottleneck will constrain the number of products that could be manufactured in parallel. This relation between scaling up production and reduction of costs is further explained in a hypothetical break-even point analysis (Figure 1). To that end, the identification of the key economic drivers in manufacturing cell therapies and their inclusion in any attempt to reduce the associated manufacturing costs can help to contain escalating prices.

\section{Preparing for lengthy development timelines and stringent regulatory requirement}

Due to the media attention that new cell therapy products attract there is high public expectation for rapid availability of the therapies. In spite of that, developers who are keen on translating novel therapeutic strategies into the clinic need to be well equipped financially in order to succeed in their efforts. Some larger commercial developers do not have any expectation of substantial revenue derived from these novel products; they instead rely on less advanced products that have a less demanding regulatory pathway or that already have an established market share, in order for them to survive financially. However, this mixed-portfolio strategy may not be feasible for small startups and academic institutions that lack a back-catalogue of such products to secure a revenue stream. Even after securing the needed funding for the long development phase, maintaining the highly-specialized GMP production facilities is very costly and requires a substantial upfront investment and the willingness to support a high burn rate of maintenance costs. This may be responsible for the very low percentage of academic developers who expect their products to be implemented into regular clinical care (18). Instead, they turn to specific fast track regulatory pathways such as the 'Hospital Exemption' and 'Specials' routes in Europe (19) to treat patients earlier, and without having to go through the burdensome process of getting the cell product to commercial scale. Other small biotech companies rely on addressing unmet medical conditions and the possibility of obtaining an orphan drug designation for their products which can speed up the regulatory approval pathway (14) and generate adequate cash flow during the pre-market period. However, this does not necessarily guarantee commercial success (20). One must also note that most academic developers are using public funds in their translational process. Therefore, the development of a much-needed novel therapeutic will be funded by taxpayer money. If attempts are to be made to accelerate the translation of such products to market, it would be necessary to license them to industrial manufacturers at a reasonable price (15), on the basis that affordable pricing should be maintained when selling such products. 
The regulatory approach for the clinical translation of any cell or gene therapy product is highly dependent on their intended clinical use, methods of manufacturing and the specific national regulations where they are being developed (21). Even though the regulatory framework for cell therapies in Europe may be perceived by some as rigid and exhaustive (22), the regulatory authorities recognize the importance of ensuring patient access to safe, effective medicines and are exerting tremendous efforts to address these concerns (23). This is evident in the introduction of the new EU clinical trials regulation which aims to harmonize the divergent regulatory requirements of the different member states in case of multistate clinical trials, among other aspects (24). Moreover, the European Commission has initiated a procedure for consultation on new guidelines on Good Manufacturing Practices, specific for advanced therapy medicinal products. Although these efforts have been positively perceived by the majority of the scientific community, they do not come without major challenges. For instance, the new EU clinical trials regulation mandates a very strict timeline for the evaluation process of clinical trial applications, which may be difficult to comply with for small academic groups developing advanced therapies (24). Also, some fear that the new GMP guideline may be intended to create double standards, depending on whether advanced therapies are manufactured by industry or by academic manufacturers (25). In either way, regulatory guidance should continue to evolve in order to prevent the growing use of unproven cell therapies that encourages medical tourism (26) and to shorten the development timelines of these therapies which, in turn, will lower their market prices. For this, academic institutions who are involved in the development of cell therapies should establish collaborations between their centers and engage in a responsible collective dialogue with the appropriate regulatory agencies to speed up their translational processes (21).

\section{Reaching a successful reimbursement rate}

Reimbursement of cell and gene therapies is currently one of the most debated topics in the adoption process of novel technologies into the medicinal products market. On one hand, if developers fail to reach a reimbursement rate that covers their incurred expenses, the product as well as the business structure behind it will never be able to survive in the open market. On the other hand, offering cell and gene therapies as highly overpriced products will not help them to achieve commercial stability through adequate market penetration (27). Immunotherapies such as antigen-specific T-cells may actually offer the patients the best chance for less toxicity, higher potency and improved quality of life in comparison to the available antiviral drug regimen (28). However, under the current methods of insurance reimbursement, such products, 
yet with limited well-defined real-world benefits, may not be seen as addressing an unmet clinical need, or their potential benefits may not outweigh their costs. A key consideration when analyzing the health economic justification for cell-based therapies is therefore the extent to which they restore function rather than simply maintain the patient or ameliorate the condition. The negation of costs of ongoing patient support, and of managing chronic comorbidities, is one of the best arguments to justify the high initial costs of prescribing cell therapies. Most importantly, not only detailed cost-effectiveness analyses accounting for the alternative costs of long-term palliative care are required for evaluating these novel interventions, but also streamlining the manufacturing process and lowering associated costs for developing such therapies would be a critical step in achieving a positive cost-benefit ratio. The recentlysuggested considerations to maximize reimbursement potential of cell and gene therapies should also be looked at early on in the development process (15). Probably some of these therapies, particularly the autologous ones, are not meant for a large scale adoption into the medicinal product market. Still, this should not hinder developers, especially academic centers, from continuing their research efforts into finding ways to address devastating diseases. In the long term, when manufacturing technologies reach a higher level of maturity, most of these challenges will be easier to overcome.

\section{A case study: $C M V$-specific $T$ cells for adoptive immunotherapy}

We performed a cost estimation of a CMV-specific $\mathrm{T}$ cell therapy manufactured in an academic GMP facility using the previously indicated costing model (Table 1A-B). To the authors' knowledge, no similar costing data exists in the public domain for such autologous cell therapy products. The cost model was employed to calculate the costs of manufacturing the cellular product using the recently developed whole protein-spanning overlapping peptide pool-based approach with CMVpp65 and IE-1 peptide (29). With a GMP manufacturing time of 21 days for a single CMV-specific peptide stimulated $\mathrm{T}$ cell line, we estimated the GMP facility indirect costs at $€ 5,670$. Direct costs were estimated at $€ 10,390$. The final price for a single CMVspecific $T$ cell line was then calculated to be $€ 16,000$.The GMP facility cost of a single $T$ cell line was then recalculated with the assumption that another $\mathrm{T}$ cell line could be produced in parallel, however under strict spatial segregation. In this case, the GMP fixed costs dropped to $€ 2,835$ for each line. The materials and supplies costs were estimated at $€ 6,190$. The remaining direct costs $(€ 4,200)$ were split between the two manufactured cell therapy products. The final price for a single $\mathrm{CMV}$-specific $\mathrm{T}$ cell product then came to $€ 11,000$ (Table 1A-B). Our case study thus demonstrates that immunotherapy may offer not only significant clinical advantages 
to immunocompromised patients, but can also be manufactured at a reasonable cost if an appropriate operational model is adopted. Our findings also mirror results from other studies examining the need to reduce the economic burden of post-transplantation care $(9,30)$.

In summary, commercialization of novel cell therapies, especially autologous products, is not a straightforward process; many challenges must be overcome, particularly for academic developers to succeed in their mission. The challenge for the sector is surviving financially through the lengthy development timelines and overcoming any regulatory hurdles while making a successful transition from a production method that has been developed during academic research to one that is sustainable in manufacturing to satisfy a potentially global market. This needs to be done in the current absence of a consensus view about what operational model to adopt and what the incurred costs will be. Therefore, it is today more important than ever to generate accurate manufacturing cost estimates that can be useful to eventually determine a reasonable price for cellular therapies and achieve the aim of producing a clinical benefit in a larger patient population. Only with the application of robust cost and operational models will it be possible to create the confidence that must underpin the required investment. Academia needs a growing cadre of commercially-aware researchers who are willing and able to act collectively at the pre-competitive stages of their work in order to generate the mature, tried-and-tested approaches to manufacture at scale that will increase patient access.

This work was partially supported by a DFG-grant: SFB-TR36, project A2.The authors declare no competing financial interests.

\section{References}

1. Leen, A. M., C. M. Bollard, A. M. Mendizabal, E. J. Shpall, P. Szabolcs, J. H. Antin, N. Kapoor, S.Y. Pai, S. D. Rowley, P. Kebriaei, B. R. Dey, B. J. Grilley, A. P. Gee, M. K. Brenner, C. M. Rooney, and H. E. Heslop. 2013. Multicenter study of banked third-party virus-specific T cells to treat severe viral infections after hematopoietic stem cell transplantation. Blood 121: 5113-23.

2. Gerdemann, U., U. L. Katari, A. Papadopoulou, J. M. Keirnan, J. A. Craddock, H. Liu, C. A. Martinez, A. Kennedy-Nasser, K. S. Leung, S. M. Gottschalk, R. A. Krance, M. K. Brenner, C. M. Rooney, H. E. Heslop, and A. M. Leen. 2013. Safety and clinical efficacy of rapidly-generated trivirus-directed $\mathrm{T}$ cells as treatment for adenovirus, EBV, and CMV infections after allogeneic hematopoietic stem cell transplant. Mol. Ther. 21: 2113-21.

3. Gottschalk, S., and C. M. Rooney. 2015. Adoptive T-cell immunotherapy. In Current Topics in Microbiology and Immunology vol. 391. 427-454.

4. Brestrich, G., S. Zwinger, A. Fischer, M. Schmück, A. Röhmhild, M. H. Hammer, A. Kurtz, L. Uharek, C. Knosalla, H. Lehmkuhl, H.-D. Volk, and P. Reinke. 2009. Adoptive T-cell therapy of a lung transplanted patient with severe CMV disease and resistance to antiviral therapy. Am. J.

Transplant. 9: 1679-84.

5. Fishman, J. A. 2007. Infection in solid-organ transplant recipients. N. Engl. J. Med. 357: 2601-14. 
6. Husain, S., C. E. Pietrangeli, and A. Zeevi. 2009. Delayed onset CMV disease in solid organ transplant recipients. Transpl. Immunol. 21: 1-9.

7. Razonable, R. R., and A. Humar. 2013. Cytomegalovirus in solid organ transplantation. Am. J. Transplant 13 Suppl 4: 93-106.

8. Razonable, R. R. 2011. Antiviral Drugs for Viruses Other Than Human Immunodeficiency Virus. Mayo Clin. Proc. 86: 1009-1026.

9. Jain, N. A., K. Lu, S. Ito, P. Muranski, C. S. Hourigan, J. Haggerty, P. D. Chokshi, C. Ramos, E. Cho, L. Cook, R. Childs, M. Battiwalla, and A. J. Barrett. 2014. The clinical and financial burden of pre-emptive management of cytomegalovirus disease after allogeneic stem cell transplantationimplications for preventative treatment approaches. Cytotherapy 16: 927-933.

10. Saglio, F., P. J. Hanley, and C. M. Bollard. 2014. The time is now: Moving toward virus-specific T cells after allogeneic hematopoietic stem cell transplantation as the standard of care. Cytotherapy 16: 149-159.

11. The European Commission. 2003. Commission Directive 2003/94/EC Laying Down the Principles and Guidelines of Good Manufacturing Practice in Respect of Medicinal Products for Human Use and Investigational Medicinal Products for Human Use. Off. J Eur Union 13: 22-26. http://ec.europa.eu/health/files/eudralex/vol-1/dir_2003_94/dir_2003_94_en.pdf

12. EudraLex-EudraLex - Volume 4 Good manufacturing practice (GMP) Guidelines. 2009. http://ec.europa.eu/health/documents/eudralex/vol-4/index_en.htm.

13. Abou-El-Enein, M., A. Römhild, D. Kaiser, C. Beier, G. Bauer, H.-D. Volk, and P. Reinke. 2013. Good Manufacturing Practices (GMP) manufacturing of advanced therapy medicinal products: a novel tailored model for optimizing performance and estimating costs. Cytotherapy 15: 362-83.

14. Hourd, P., P. Ginty, A. Chandra, and D. J. Williams. 2014. Manufacturing models permitting roll out/scale out of clinically led autologous cell therapies: Regulatory and scientific challenges for comparability. Cytotherapy 16: 1033-1047.

15. Abou-El-Enein, M., G. Bauer, and P. Reinke. 2014. The business case for cell and gene therapies. Nat. Biotechnol. 32: 1192-1193.

16. Octane Technology. http://octaneco.com/octane-download.pdf.

17. Bajgain, P., R. Mucharla, J. Wilson, D. Welch, U. Anurathapan, B. Liang, X. Lu, K. Ripple, J. M. Centanni, C. Hall, D. Hsu, L. a Couture, S. Gupta, A. P. Gee, H. E. Heslop, A. M. Leen, C. M.

Rooney, and J. F. Vera. 2014. Optimizing the production of suspension cells using the G-Rex "M" series. Mol. Ther. Methods Clin. Dev. 1: 14015.

18. de Wilde, S., L. Veltrop-Duits, M. Hoozemans-Strik, T. Ras, J. Blom-Veenman, H.-J. Guchelaar, M. Zandvliet, and P. Meij. 2016. Hurdles in clinical implementation of academic Advanced Therapy Medicinal Products: A national evaluation. Cytotherapy doi:10.1016/j.jcyt.2016.02.010.

19. Cuende, N., C. Boniface, C. Bravery, M. Forte, R. Giordano, M. Hildebrandt, A. Izeta, and M. Dominici. 2014. The puzzling situation of hospital exemption for advanced therapy medicinal products in Europe and stakeholders' concerns. Cytotherapy 16: 1597-1600.

20. Hall, A. K., and M. R. Carlson. 2014. The current status of orphan drug development in Europe and the US. Intractable rare Dis. Res. 3: 1-7.

21. Abou-El-Enein, M., G. Bauer, P. Reinke, M. Renner, and C. K. Schneider. 2014. A roadmap toward clinical translation of genetically-modified stem cells for treatment of HIV. Trends Mol. Med. 20: 632-642.

22. Blasimme, A., and E. Rial-Sebbag. 2013. Regulation of Cell-Based Therapies in Europe: Current Challenges and Emerging Issues. Stem Cells Dev. 22: 14-19.

23. Maciulaitis, R., L. D’Apote, A. Buchanan, L. Pioppo, and C. K. Schneider. 2012. Clinical development of advanced therapy medicinal products in Europe: evidence that regulators must be proactive. Mol. Ther. 20: 479-82. 
24. Abou-El-Enein, M., and C. K. Schneider. 2016. Deciphering the EU clinical trials regulation. Nat. Biotechnol. 34: 231-233.

25. The European Commission. 2015. Summary of the responses to the targeted stakeholder consultation on the development of Guidelines on Good Manufacturing Practice for Advanced Therapy Medicinal Products pursuant to Article 5 of Regulation 1394/2007.

http://ec.europa.eu/health/files/advtherapies/2015_11_pc_gmp_atmp/2015_11_pc_gmp_atmp_summar y.pdf.

26. Srivastava, A., C. Mason, E. Wagena, N. Cuende, D. J. Weiss, E. M. Horwitz, and M. Dominici. 2016. Part 1: Defining unproven cellular therapies. Cytotherapy 18: 117-119.

27. Abou-El-Enein, M., G. Bauer, and P. Reinke. 2015. Gene therapy: A possible future standard for HIV care. Trends Biotechnol. 33: 374-376.

28. Cruz, C. R., P. J. Hanley, H. Liu, V. Torrano, Y.-F. Lin, J. A. Arce, S. Gottschalk, B. Savoldo, G. Dotti, C. U. Louis, A. M. Leen, A. P. Gee, C. M. Rooney, M. K. Brenner, C. M. Bollard, and H. E. Heslop. 2010. Adverse events following infusion of T cells for adoptive immunotherapy: a 10-year experience. Cytotherapy 12: 743-9.

29. Hammer, M. H., S. Meyer, G. Brestrich, A. Moosmann, F. Kern, L. Tesfa, N. Babel, A. Mittenzweig, C. M. Rooney, W. Hammerschmidt, H.-D. Volk, and P. Reinke. 2005. HLA typeindependent generation of antigen-specific T cells for adoptive immunotherapy. Eur. J. Immunol. 35: 2250-8.

30. Hiwarkar, P., H. B. Gaspar, K. Gilmour, M. Jagani, R. Chiesa, N. Bennett-Rees, J. Breuer, K. Rao, C. Cale, N. Goulden, G. Davies, P. Amrolia, P. Veys, and W. Qasim. 2013. Impact of viral reactivations in the era of pre-emptive antiviral drug therapy following allogeneic haematopoietic SCT in paediatric recipients. Bone Marrow Transplant. 48: 803-808. 


\begin{tabular}{|c|c|c|}
\hline Variable Resources & Description & Variable costs $(€)$ \\
\hline \multirow{3}{*}{$\begin{array}{l}\text { Materials and } \\
\text { supplies }\end{array}$} & Media and supplements \& Plasticware & 5,660 \\
\hline & $\begin{array}{l}\text { Reagents for the CliniMacs } \\
\text { - PepMix HCMVA (pp65) } \\
\text { - PepMix HCMVA (IE-1) }\end{array}$ & 420 \\
\hline & Garments & 110 (10 sets) \\
\hline Personnel & Production personnel & 2,200 \\
\hline \multirow{2}{*}{$\begin{array}{l}\text { Utilities } \\
\text { Maintenance }\end{array}$} & Electricity, water \& medical grade gases & \multirow[t]{2}{*}{350} \\
\hline & Corrective maintenance & \\
\hline \multirow[t]{3}{*}{$\begin{array}{l}\text { Quality } \\
\text { Management } \\
\text { system }\end{array}$} & $\begin{array}{l}\text {-Depreciation of media-fill, process } \\
\text { validation and fees for manufacturing } \\
\text { authorization }\end{array}$ & \multirow[t]{3}{*}{1,650} \\
\hline & -Cleaning and environmental monitoring & \\
\hline & $\begin{array}{l}\text { Batch Release Testing (testing for sterility, } \\
\text { mycoplasma, endotoxin and other items } \\
\text { required by the guidelines) }\end{array}$ & \\
\hline Total & & 10,390 \\
\hline
\end{tabular}

Table 1: The variable costs of manufacturing GMP-grade CMV-specific T cell products. The variable resources of the manufacturing process were identified according to the cost model.

\begin{tabular}{|l|l|l|l|}
\hline & $\begin{array}{l}\text { Unit fixed costs } \\
(\boldsymbol{\epsilon})\end{array}$ & $\begin{array}{l}\text { Unit variable cost } \\
(\boldsymbol{(})\end{array}$ & $\begin{array}{l}\text { Total unit cost } \\
(\boldsymbol{\epsilon})\end{array}$ \\
\hline CMV-specific CTL (1 line/lab) & $5,670(35 \%)$ & $10,390(65 \%)$ & 16,060 \\
\hline $\begin{array}{l}\text { CMV-specific CTL (2 } \\
\text { lines/lab) }\end{array}$ & $2,835(25 \%)$ & $8,290(75 \%)$ & 11,125 \\
\hline
\end{tabular}

Table 1-B: The fixed and variable cost shares in the manufacturing of a single $\mathrm{CMV}$-specific $\mathrm{T}$ cell product. The fixed costs represent $35 \%$ while the variable costs represent $65 \%$ of the total manufacturing costs. If $2 \mathrm{CMV}$ - specific $\mathrm{T}$ cell products are produced in the same GMP laboratory, the fixed costs represent $25 \%$ of the total manufacturing costs. 


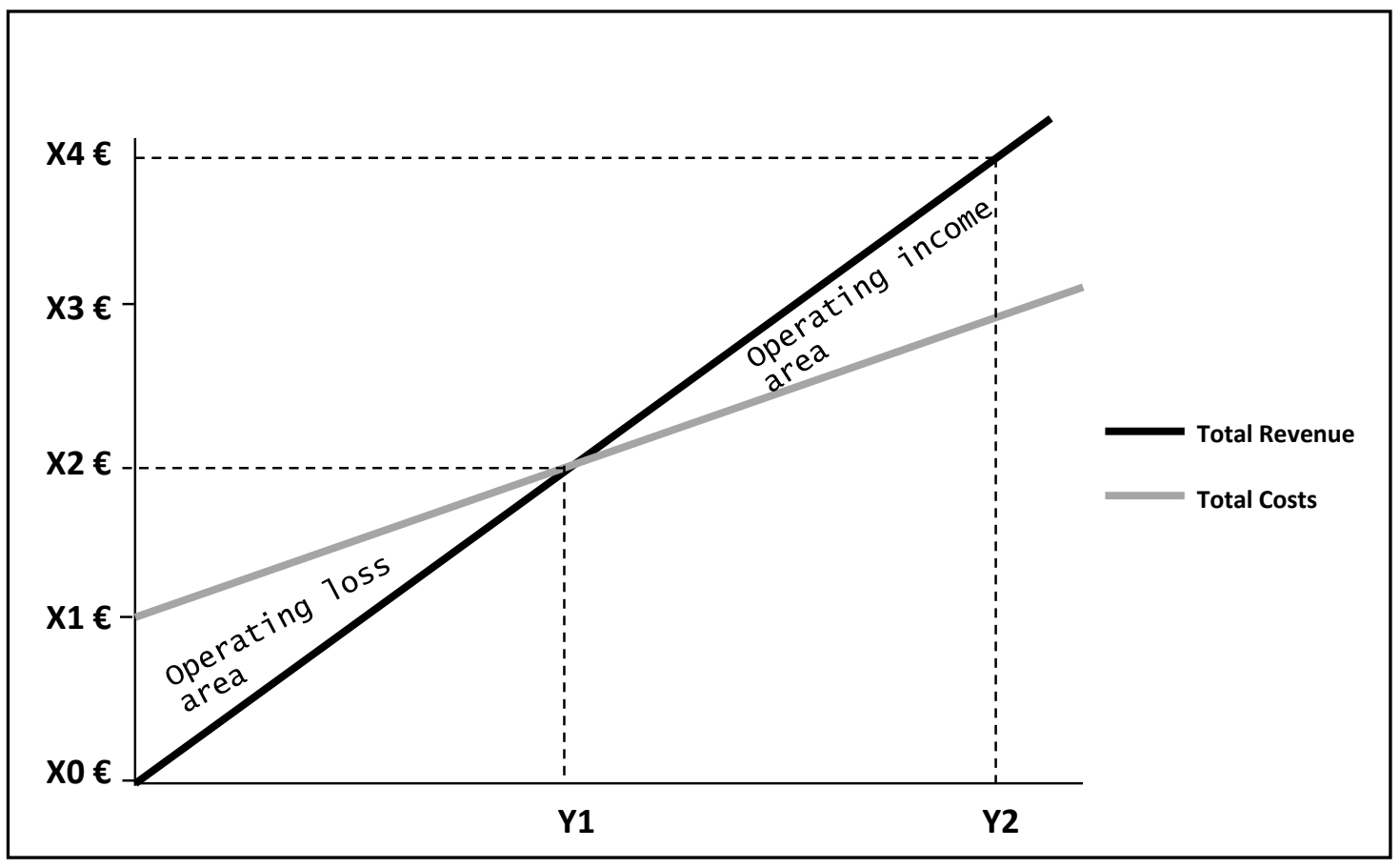

Figure 1: A hypothetical break-even analysis of manufacturing GMP-grade cell therapy products. The figure presents a cost-volume-profit graph for GMP grade cell lines. Notice that when no cells are produced, fixed costs are $\mathrm{X} 1 €$, resulting in a loss of $100 \%$ of these costs per year. As manufacturing volume increases, the loss decreases by the contribution margin for each cell line produced. The cost and revenue lines intersect at the break-even point, which means zero loss and zero profit (fixed and variable costs are covered). Then, as manufacturing increase beyond this break-even point, we see an increase in income. The unit contribution of fixed costs decreases by half (X4 €) when the production volume reaches Y2. This point can be reached, for instance, by producing two parallel cell lines in one GMP laboratory using strict spatial separation. 